\title{
Comparison of Early Maladaptive Schemas in Patients with Obsessive-Compulsive Disorder, Patients with Obsessive-Compulsive Personality Disorder with Healthy Individuals
}

\author{
Mehrdad Shariatzadeh ${ }^{*}$ \\ Shahram Vaziri² \\ Malek Mirhashemi ${ }^{3}$
}

\begin{abstract}
${ }^{1} \mathrm{PhD}$ in Psychology, Psychology Department, Islamic Azad University, Roudehen Branch, Roudehen, Iran
Email: mehrdad.shariatzadeh@gmail.com

${ }^{2}$ PhD in Psychology, Psychology Department, Islamic Azad University, Roudehen Branch, Roudehen, Iran

${ }^{3} \mathrm{PhD}$ in Psychology, Psychology Department, Islamic Azad University, Roudehen Branch, Roudehen, Iran
\end{abstract}

Doi:10.5901/mjss.2015.v6n4s2p171

\section{Abstract}

Objective: Early maladaptive schemas (EMSs) fundamental beliefs that underpin stable and trait-like psychological disorders are chronic and relapsing. In our research, active schemas in Obssessive-Compulsive patients with Obssessive Compulsive Pesrsonality patients have been compared with healthy individuals. The purpose of this study was to compare early maladaptive schemas Young $(2003,1990)$ in OCD patients with OCPD patients and healthy subjects. Method: For this study, 38 patients with Obssessive Compulsive disorder and 44 patients with Obssessive Compulsive Personality disorder during the year who referred to medical centers and clinics in Kermanshah city were selected through structured interviews and the Yele Braown Obssessive Compulsive Scale (Y-BOCS), and 63 patients from diagnosis for mild problems who referred to the clinic were considered as controls. 15 early maladaptive schemas through Young Schema Questionnaire-Short Form (YSQ-SF) were measured. Results: Analysis of variance showed that maladaptive schemas are different in the three groups. All maladaptive schemas except Self-sacrifice, and insufficient self-control in both group of patients were significantly higher than in healthy individuals. The results indicate that differences between individuals with obssessive-compulsive disorder and healthy control in schemas of emotional deprivation, mistrust, social isolation, Failure to achieve, Dependence, Vulnerability to harm, Subjugation, Emotional inhibition, and Unrelenting standards were statistically significant. The obssessive compulsive personality disorder group significantly obtained higher scores than the obssessive compulsive disorder group in 13 schemes. Also the obssessive compulsive personality disorder group obtained higher scores compared to the healthy control group in the total score of schemas. Conclusion: The findings of the present study suggest that, in the OCD and OCPD patients, all maladaptive schemas except Self-sacrifice, and insufficient self-control indicated higher scores. The effect size in this study shows that in both disorders schemas and schemas of vulnerability to harm and illness to have the greatest impact.

Keywords: Early Maladaptive Schemas, obsessive compulsive disorder, obsessive compulsive personality disorder.

\section{Introduction}

Among patients with anxiety disorders, Obsessive compulsive disorder (OCD) sufferers are likely to have the greatest number of patient hospitalized (Barlow \& Duran, 2015). Lifetime prevalence of OCD is estimated from 1.6\% to $2.3 \%$ (Calamari, Chik, Pontarelli, \& DeJong, 2012; Kessler, Berglund, et al., 2005), and the 1-year prevalence of the disorder is estimated to be 1\% (Calamari et al., 2012; Kessler, Chiu, et al., 2005). Beck and Clark (2010) suggested that cognitive vulnerability to anxiety due to repeated experiences of neglect, abandonment, humiliation and psychological trauma occurs in childhood and adolescence. According to the cognitive point of view, there are maladaptive cognitive schemas and faulty appraisals are important processes in the etiology and persistence of obsessions and compulsions considered (Clark and Beck, 2010). Olatunii, Cisler, and Tolin (2007) found that people with anxiety disorders compared to nonanxious significantly lower quality of life experience, and impaired quality of life for all anxiety disorders have been reported almost identical. And OCD is located at the top of these disorders. In addition to the theoretical debate on the relationship between obsessive - compulsive personality disorder and obsessive - compulsive disorder, a growing volume of research has also it's too much comorbidity between these two disorders have revealed. For example, studies on the diagnostic criteria for DSM-IV comorbidity of OCD with obsessive-compulsive personality disorder are estimated to be 
around 23 to 32 percent (Albert, Maina, Forner, \& Bogetto, 2004; Coles, Pinto, Mancebo, Rasmussen and et al., 2008). Research also recently Starcevic et al. (2013) reported that $47.3 \%$ of the comorbidity of these disorders (Starcevic, Berle, Brakoulias, Sammut \& et al., 2013). There is clear evidence of personal beliefs or schemas about threats and vulnerabilities as predisposing factors for anxiety disorders support. There is emerging evidence that enduring beliefs or schemas about threat and personal vulnerability are predisposing factors to anxiety disorders. Although research on the cognitive model of anxiety vulnerability is still in the preliminary stages, significant progress in recent years in establishing the causal abstinent for fear in anxiety have been achieved (Beck et al. 2011). Nevertheless, early maladaptive schemas (EMS) organise the principles of giving appraisal and meaning to experiences and have not previously been investigated in OCD populations (Furlong, 2006).

According to cognitive theory, schemas called cognitive structures that lead screening, code and assessment of stimulus input. Based on schemas, to the parties themselves, and their experiences are interpreted in a meaningful way. Schemes over a long period of life extending and be extended (Beck, 1976; Guidano \& Liotti, 1983). If in the course of development ,people experience very negative environmental experience (e.g., abandonment, abuse, or neglect), may have created distorted views about self, others and the world around and contribute to the formation of maladaptive schemas (Beck, Freeman, Davis, et al., 2006).

For Young (2003), early maladaptive schemas (EMS) are, stable, broad, pervasive themes regarding oneself and one's relationship with others, developed during childhood, and elaborated throughout one's lifetime, and dysfunctional to a significant degree (Young et al., 2003). Maladaptive schemas result in the production of negative feelings, such as depression and anxiety (Young, 1999). When schemas are latent, they have no role in information processing. When activated, they channel cognitive processing from the first to the last stages (Beck et al., 2004). Schemas are not always positive and adaptive: They may also be negative and maladaptive (Young et al., 2003).

Young et al. have identified 18different EMSs to date, each with its own proposed origin and long-term impact. The18 EMSs are grouped into five umbrella categories known as schema domains ,bringing together the EMSs that tend to develop together. Every domain represents one important part of the core needs of the child. Childhood neglect, adversities, maltreatment and abuse produce, for example, EMSs like Abandonment/ Instability (AB), Mistrust/ Abuse (MA) or Emotional Deprivation (ED) which belong to the Disconnection and Rejection schema domain according to the SFT (Young, 1999; Young et al.,2003).

In study of Sookman, Pinard, Beck (2001) as Vulnerability Schemas in Obsessive-Compulsive Disorder elaborates on the construct of dysfunctional vulnerability schemas in Obsessive-Compulsive Disorder (OCD). Four domains of beliefs are hypothesized to comprise vulnerability in OCD: Perceived Vulnerability; View of/Response to Unpredictability, Newness, and Change; View of Strong Affect; and Need for Control. A study carried out with 111 subjects indicated that OCD patients more strongly endorsed these beliefs compared with patients with other anxiety disorders, mood disorders, and normal controls. The discriminant function derived from these four belief domains was effective in classifying OCD patients and other subjects into their respective groups. The results support the inclusion of dysfunctional vulnerability beliefs in cognitive assessment and treatment of OCD. Atalay, Atalay, Karahan, and Çakiskan (2008) compared EMSs among patients with OCD and healthy controls. OCD patients scored significantly higher than controls on 11 of 18 EMSs. The greatest differences were observed for Social Isolation, Vulnerability to Harm or IIIness, and Negativity/Pessimism. The severity of OCD symptoms was significantly correlated only with the Dependence/Incompetence EMS, with none of the other EMSs even approaching statistical significance. Noie, Asgharnezhad Farid, Fata, \& Ashoori (2010) compared "Early Maladaptive Schemas" and their parental origins in individuals with obsessive-compulsive disorder, obsessivecompulsive personality disorder and non-clinical sample. The research was a post-hoc (causal-comparative) crosssectional study that was carried out on a sample of 45 subjects (including 15 patients with OCD and 15 patients with OCPD and 15 non-clinical individuals) who were selected using convenience sampling. The subjects were assessed using Young Maladaptive Schema Questionnaire and Young Parenting Inventory. Data were analyzed using MANOVA and descriptive statistics. Results showed significant difference among clinical groups and the non-clinical sample in early maladaptive schemas. The results of this study also suggest that the two clinical groups are similar deep cognitive constructs. Therefore, this study supports relationship between these disorders (OCD and OCPD). Another study compared EMSs in OCD and in trichotillomania (TTM) (Lochner et al., 2005). OCD participants $(n=33)$ scored significantly higher than the TTM group $(n=26)$ on Mistrust/Abuse, Social Isolation, Defectiveness/Shame, Subjugation, and Emotional Inhibition, with a nonsignificant trend toward a higher score for Vulnerability to Harm or Illness. OCD patients reported more childhood trauma, disability, and comorbidity, but also better response to treatment. Unfortunately, because there was no healthy control group, it was not possible to identify EMSs elevated among both disorders. In study of Kim, Lee \& Lee (2014) as Relationship between early maladaptive schemas and symptom dimensions in patients with obsessive- 
compulsive disorder on a sample of fifty-seven patients with OCD and 70 normal controls completed the Young Schema Questionnaire, the Yale-Brown Obsessive Compulsive Scale (Y-BOCS), the Y-BOCS symptom checklist, and the Beck Depression Inventory. Patients with OCD had significantly higher scores for schema related to defectiveness/shame, social isolation/alienation, and failure than did normal controls. Among the five OCD symptom dimensions, the sexual/religious dimension was only significantly correlated with two schemas of vulnerability to harm or illness and enmeshment/undeveloped self. These two schemas were significant predictors of the sexual/religious dimension, accounting for $33 \%$ of the total variance in this dimension. Any EMSs in patients with OCD were not related to clinical variables such as severity of OCD and duration of illness. These findings may constitute evidence to improve our understandings of OCD from a perspective of schema theory. In study of esmaeeli, sohrabi, borjali and farokhi (2010) by activated EMSs in a sample comprised 42 patients with OCD 33 women, 9 men, and 70 healthy people as control group via convenient sampling method selected. Data gathering was done using Y-BOCS, Structured Clinical Interview for DSM-IV axis-I disorders (SCID-I) and Symptom Checklist-90-Revised, Obsessive-Compulsive Symptoms (SCL-90-ROCS), Young Parenting Inventory (YPI), and Young Schema Questionnaire - Short Form (YSQ-SF). The results showed significant difference among clinical groups and the non-clinical sample in early maladaptive schemas. In addition results shows that in patient with OCD, schemas of Entitlement, Unrelenting Standards, Mistrust/Abuse, and Vulnerability to harm and illness was actived. In the research of Talee-Baktash, Yaghoubi, \& Yousefi (2013) Compared the early maladaptive schemas and cognitive emotion regulation strategies in obsessive-compulsive disorder patients and healthy controls. Results shows that compared with healthy subjects OCD patients received the higher scores in early maladaptive schemas. In the research of Wilhelm, Berman, Keshaviah, Schwartz, \& et al. (2015) results indicated that perfectionism and certainty obsessive beliefs and maladaptive schemas related to dependency and incompetence significantly mediated (improved) treatment response. In conclusion, cognitive changes in perfectionism/certainty beliefs and maladaptive schemas related to dependency/incompetence precede behavioral symptom reduction for OCD patients. Targeting these mechanisms in future OCD treatment trials will emphasize the most relevant processes and facilitate maximum improvement. In the review research of Weingarden, \& Renshaw (2015) shame schema were compared in patients with OCD and related disorders. They provide an overview of shame, its measurement considerations, and a full review of 110 articles addressing shame in OCRDs. Results show that much of the current knowledge on shame in OCRDs comes from anecdotal, case, and conceptual work. Empirical studies do not always assess specific types of shame, instead assessing shame as a general construct.

Therefore, the aim of this study was to investigate the presence of EMSs in patients with Obssessive Compulsive disorder and compare their schematic structure with a group of normal controls and a group of patients with Obssessive Compulsive Personality disorder.

In the present study, we have sought to test the following hypotheses:

1. There is significant difference between maladaptive schemas in patients with obssessive compulsive disorder and patients with obssessive compulsive personality disorder and healthy subjects.

2. Maladaptive schemas in patients with obssessive compulsive disorder and patients with obssessive compulsive personality disorder more frequent than in normal subjects.

3. Mean score of maladaptive schemas in patients with obsessive compulsive personality disorder is higher than patients with obsessive-compulsive disorder.

\section{Method}

This is a causal - comparative or ex post facto study. Research variables through the standardized questionnaire and structured clinical interviews were measured, and the differences between the groups were analyzed by ANOVA test.

\section{Participants}

Participants in this study have been chosen from patients who referred to psychological counseling centers in Kermanshah. Conditions of entry into the study were (1) Having OCD or obsessive-compulsive personality disorder is diagnosed by a psychiatrist or clinical psychologist based on DSM-IV criteria or healthy a person; (2) Not having other mental disorders and; (3) At least Middle school diploma education. Exclusion criteria from the study were (1) Low education; (2) Having combined disorders; and (3) It does not specify the type of mental disorder or not having mental health measures. The control group of clients who have not seen any signs or symptoms of disease were selected. The study sample was referred to psychological or psychiatric clinics in Kermanshah, who had one of OCD or obsessivecompulsive personality disorder. Samples are available research referring to psychological and psychiatric clinics in 
Kermanshah were selected. The total sample size was 140 . The total sample size was 140.38 patients with obssessive compulsive and 44 patients with obssessive compulsive personality disorder, from October 2013 to the end of September 2014 were visited in health centers and 58 non- patients, who had clinically no impairment, were selected as controls. Total sample size was 140 . From this sample, $46.1 \%$ were female, and $53.9 \%$ male. Informed consent was delivered to all participants, and the participants were assured that the information provided by them will be kept be treated confidentially.

In the study, the age range of participants was 20 to 40 years (and the mean age 27.24 years, and their median age 29 years). Then, structured clinical interview for DSM IV axis 1 disorders (SCID-I), Structured clinical interview for DSM IV personality disorders (SCID-II), Yale-Brown Obsessive Compulsive Scale (Y-BOCS), and Young Schema Questionnaire- Short Form (YSQ-SF) were used to examine the patients.

\section{Materials}

Patients in this study were enrolled based on the Structured Clinical Interview for DSM-IV Axis I \&II Disorders (SCID-I and SCID-II). Then, Yale-Brown Obsessive Compulsive Scale (Y-BOCS), and Young Schema Questionnaire- Short Form (YSQ-SF) were used to examine the patients.

Structured Clinical Interview for DSM-IV Axis I (SCID-I)

SCID and its versions were considered to be the most comprehensive and structured diagnostic interviews which were available. In fact, they were new and wide range utility instruments, in 1987 by Spitzer, Gibbon, Williams and built in compliance with the criteria of the DSM-IV (Groth-Marnat, 2009). Due to high accuracy of the diagnostic criteria and extraordinary compliance with DSM-IV, the codification was translated to and adapted with different languages. The Persian translation of the SCID-I (the clinician version: SCID-CV) was utilized in this study. The Persian version has been normalized and its assessment has shown that diagnostic agreements between test and retest SCID administration are fair to good for most diagnostic categories. Overall weighted kappa was 0.55 for lifetime diagnoses. Specificity values for most psychiatric disorders were high (over 0.85 ) and the sensitivity values were somewhat lower (Sharifi, Assadi, Mohammadi, Amini, et al., 2007).

The Structured Clinical Interview for DSM-IV Axis II (SCID-II)

The second version of the Structured Clinical Interview (First, Spitzer, Gibbon, \& Williams, 1996) for measuring eleven personality disorders, including obsessive - compulsive personality disorder, designed. In study of Lobestal, Leurgans, \& Arntz (2011) tested inter-rater reliability of SCID I and SCID II that were simultaneously assessed in a sample of $\mathrm{N}=151$ participants. Results revealed moderate to excellent inter-rater agreement of the Axis I disorders, while most categorically and dimensionally measured personality disorders showed excellent inter-rater agreement. In Iran SCID-II and SCID-IIPQ have been translated and adapted by Mohammadkhani, Jokar, Jahani-tabesh, and Tamannaeifar (2011). Studies of test-retest reliability and inter-rater consistency refer to the intermediate results. For instance, the inter-rater consistency of SCID-II for general diagnostic cases was between $0.40-0.86$, with an average of 0.59 . Since SCID was made consistent with DSM-IV diagnostic criteria, it could be assumed to be valid.

\subsection{Yale-Brown Obsessive Compulsive Scale (Y-BOCS),(Goodman, Price, \& Rasmussen, 1989)}

A semi-structured clinical interview to assess the severity of obsessive and compulsive, regardless of the number and content of obsessions and current compulsion. Yale-Brown Obsessive Compulsive Scale has two parts: a symptom checklist (SC) and the symptom severity (SS) scale. 16 items of SC is on a five-point Likert scale and self-report answered. SS obsession and compulsion in any of the five dimensions of the disturbance frequency, interference, resistance and control of symptoms are estimated. Y-BOCS gives three scores: Obsessions, compulsions intensity and a total score that includes all the items (Goodman et al., 1989). Today (Y-BOCS) tool for screening of patients with OCD and has been used in many studies. Inter-rater reliability and test-retest (YBOCS) to assess the symptoms of OCD, but not in other disorders and depression have been reported suitable (Woody, Steketee, \& Chambless, 1994; Tek, Ulu, \& Gürsoy Rezaki, 1995). (Y-BOCS) was translated into 13 languages, and the reliability and validity of this scale in the research (Calamari, Wiegartz, \& Janeck,1999; Moritz, Meie, \& Kloss, 2002; Arrindell, Vlaming, Eisenhardt, \& Berkum, 2002; Feinstein, Fallon, Petkova, \& Liebowitz, 2003; Deacon, \& Abramowitz, 2005; Storch, Shapira, Dimoulas, Geffken, \& et al.,2005; Rosario-Campos, Miguel, Quatrano, Chacon, \& et al.,2006; Stein, Andersen, \& Overo, 2007; Cullen, \& Brown, 2007; Pinto, 2008) and many cultures (Mollard, Cottraux, \& Bouvard, 1989; Nakajima, 1999; Woody, Steketee, \& Chambless,1994; Rosas, Vega-Dienstmaier, Suarez, Vidal, \& et al.,2002; Jacobsen, Kloss, Fricke, Hand, \& et al.,2003) have been studied. In Iran only 3 study (Mohammad-khani, 1991; Bigham, 2000; Rajezi-Esfahani, Motaghipour, Kamkari, 
Zahiredin, et al., 2012) content validity (Y-BOCS) and the reliability of this scale are studied.

\subsection{Early Maladaptive Schemas Scale: Young Schema Questionnaire- Short Form (SQ-SF, Young, 1998)}

The schema questionnaire-short form (SQ-SF) assesses 15 EMSs. The scales consist of five items with the highest loadings on the 15 factors that are emerged in a factor analysis of the long-form of the SQ (Schmidt et al., 1995). EMSs are grouped in five broad domains: disconnection and rejection (abandonment, mistrust, emotional deprivation, defectiveness, social isolation), impaired autonomy and performance (dependence, vulnerability, enmeshment, failure), impaired limits (entitlement, insufficient self-control), other directedness (subjugation, self-sacrifice, approval-seeking), and overvigilance and inhibition (negativity, emotional inhibition, unrelenting standards, punitiveness). Respondents are asked to rate statements on a six point Likert scale from "completely untrue of me" to "describe me perfectly". In Iran, Ghiasi (2008) studied the validity of the scale, and it has shown. Ghiasi (2008) has reported coefficient alpha for this scale $(a=0.94)$ and the coefficients for the subscales between $0.60-0.90$. Also, the discriminant validity and convergent validity of the YSQ-SF with dysfunctional attitudes scale are shown. In the study of Ahi (2006), the validity of this scale was obtained between $0.62-0.90$. Also, the research of shariatzadeh, vaziri, and mirhashemi (2014) confirmed that the validity of this questionnaire have been a factor.

\subsection{Procedure}

Non-hospitalized obssessive compulsive patients, obssessive compulsive personality patients after diagnosis via structured clinical interviews, completed research questionnaires. Control group were healthy subjects who referred to a counseling clinic for mild problems, and the questionnaires were completed.

\section{Resoults}

\subsection{Statistical Analysis}

Kolmograph-Smirnov test showed that our data had normal distribution. Hence, to assess the statistical significance of the differences between obssessive compulsive patients, obssessive compulsive pesonality patients and normal subjects, ANOVA test was used. Statistical analysis was done using SPSS version 21 and differences were considered significant with $P<0.05$. Data from the questionnaires were analyzed by SPSS v 21 software. The variables were tested for normality of distribution, and outliers were removed from the analysis. The descriptive parameters including mean and SD were calculated (Table 1).

Cronbach's alpha reliability of the total scale method $(\alpha=0.87)$ was obtained, and the coefficient for the questionnaire was adequate and appropriate. The lowest alpha was for insufficient self-control subscale $(\alpha=0.74)$, and the highest alpha belonged to subscales of failure $(a=0.92)$. All reliability coefficients were acceptable, and reliability coefficient for the total scale was sufficient. To examine demographic differences, one-way analysis of variance test (ANOVA) and t-tests were performed. ANOVA test results showed that early maladaptive schemas between single, married, and divorced, had no significant differences. It was also found that early maladaptive schemas between Diploma, Bachelor, and Masters had no significant differences. 
Table 1: Table of descriptive statistics for maladaptive schemas in patients with obssessive compulsive disorder, obssessive compulsive personality disorder and healthy control subjects.

\begin{tabular}{lcccccc}
\hline \hline \multicolumn{1}{c}{ Variables } & \multicolumn{7}{c}{ Group } \\
\multicolumn{1}{c}{ Maladaptive Schemas } & \multicolumn{2}{c}{ OCD } & \multicolumn{2}{c}{ OCPD } & \multicolumn{2}{c}{ Health } \\
\cline { 2 - 7 } & Mean & St.D & Mean & St.D & Mean & St.D \\
\hline Emotional Deprivation & 10.02 & 7.51 & 18.16 & 4.92 & 10.90 & 6.25 \\
Abandonment & 14.64 & 5.08 & 18.37 & 5.26 & 13.67 & 7.34 \\
Mistrust/Abuse & 12.59 & 8.90 & 18.26 & 4.96 & 10.34 & 4.52 \\
Social Isolation & 10.59 & 5.93 & 15.89 & 5.69 & 8.09 & 5.92 \\
Defectiveness / shame & 7.43 & 5.80 & 12.03 & 5.31 & 7.02 & 3.73 \\
Failure to achieve & 9.36 & 6.00 & 16.74 & 4.06 & 7.12 & 2.61 \\
Dependence & 22.14 & 6.03 & 21.89 & 6.45 & 17.21 & 5.26 \\
Vulnerability to harm & 9.64 & 6.30 & 16.92 & 3.71 & 8.00 & 4.38 \\
Subjugation & 16.05 & 5.45 & 12.92 & 7.88 & 12.50 & 6.24 \\
Self-sacrifice & 9.61 & 7.71 & 14.97 & 4.19 & 8.16 & 3.58 \\
Emotional inhibition & 18.59 & 4.98 & 22.82 & 5.63 & 17.86 & 5.30 \\
Enmeshment & 13.05 & 6.17 & 17.05 & 6.31 & 11.53 & 5.97 \\
Unrelenting standards & 17.82 & 6.04 & 19.87 & 7.35 & 19.41 & 5.28 \\
Entitlement / grandiosity & 13.95 & 7.55 & 16.92 & 5.36 & 14.33 & 6.14 \\
Insufficient self-control & 12.45 & 6.23 & 16.61 & 4.03 & 10.98 & 4.41 \\
Whole schemes & 185.48 & 72.68 & 251.42 & 43.18 & 168.19 & 40.62 \\
\hline \hline
\end{tabular}

To examine the first specific hypotheses, results (Table 2) showed that all schemas, except Self-sacrifice ( $F=1.3$; $D F=2,137 ; P=0.0 .275)$, and Insufficient self-control $(F=2.662 ; D F=2,137 ; P=0.073)$ were higher in patients than in healthy individuals. In other words, schemas of abandonment, emotional deprivation, abandonment, mistrust/abuse, social isolation, defectiveness/shame, failure to achieve, dependence, vulnerability to harm, subjugation, self-sacrifice, emotional inhibition, enmeshment, and insufficient self-control of patients with OCD and obsessive-compulsive personality disorder patients obtained significantly higher score.

Eta squared coefficient indicates that the effect of group (illness or health) on maladaptive schemas is effective. In other words, all maladaptive schemas except Self-sacrifice, and insufficient self-control in patients were significantly higher than in healthy individuals. Thus, according to the findings of Table 2, there is sufficient evidence to confirm the first hypothesis that "the three groups have statistically significant differences in the maladaptive schemas".

Table 2: Results of ANOVA for comparison of two groups of patients with obssessive-compulsive disorder, obssessivecompulsive personality disorder and healthy control

\begin{tabular}{lcccc}
\hline Maladaptive schemas & Df & $F$ & P value & $\eta^{2}$ \\
\hline Emotional Deprivation & 2,137 & 20.929 & 0.000 & 0.234 \\
Abandonment & 2,137 & 6.964 & 0.001 & 0.092 \\
Mistrust/Abuse & 2,137 & 19.459 & 0.000 & 0.221 \\
Social Isolation & 2,137 & 20.602 & 0.000 & 0.231 \\
Defectiveness / shame & 2,137 & 13.702 & 0.000 & 0.167 \\
Failure to achieve & 2,137 & 61.931 & 0.000 & 0.475 \\
Dependence & 2,137 & 11.488 & 0.000 & 0.144 \\
Vulnerability to harm & 2,137 & 41.996 & 0.000 & 0.380 \\
Subjugation & 2,137 & 3.986 & 0.021 & 0.055 \\
Self-sacrifice & 2,137 & 1.300 & 0.276 & 0.019 \\
Emotional inhibition & 2,137 & 10.704 & 0.000 & 0.136 \\
Enmeshment & 2,137 & 9.473 & 0.000 & 0.121 \\
Unrelenting standards & 2,137 & 20.746 & 0.000 & 0.232 \\
Entitlement / grandiosity & 2,137 & 15.683 & 0.000 & 0.186 \\
Insufficient self-control & 2,137 & 2.662 & 0.073 & 0.037 \\
Whole schemes & 2,137 & 30.839 & 0.000 & 0.310 \\
\hline
\end{tabular}

To test the second hypotheses of the independent, t-test was performed. The results (Table 3 ) indicate that differences 
between individuals with obssessive-compulsive disorder and healthy control in schemas of emotional deprivation $(t=3.765 ; d f=100 ; P=0.00)$, mistrust $(t=2.353 ; d f=99.705 ; P=0.021)$, social isolation $(t=2.152 ; d f=100 ; P=0.032)$, Failure to achieve ( $t=3.195 ; d f=69.013 ; P=0.002)$, Dependence ( $t=4.251 ; d f=100 ; P=0.00)$, Vulnerability to harm ( $t=1.993 ; D F=100$; $P=0.049$ ), Subjugation ( $t=2.457 ; D F=80.048 ; P=0.016)$, Emotional inhibition ( $t=4.352 ; D F=100 ; P=0.00)$, and Unrelenting standards ( $\mathrm{t}=4.221 ; \mathrm{DF}=74.707 ; \mathrm{P}=0.000$ ) were statistically significant.

Table 3: Results of $t$ test for comparison of two groups of patients with obssessive-compulsive disorder and healthy control

\begin{tabular}{lccc}
\hline \hline \multirow{2}{*}{ EMSs } & \multicolumn{3}{c}{ t-test for Equality of Means } \\
\cline { 2 - 4 } & $\mathrm{t}$ & $\mathrm{df}$ & $\mathrm{P}$ value \\
\hline Emotional deprivation & 3.765 & 100 & 0.000 \\
Abandonment & 0.772 & 99.705 & 0.442 \\
Mistrust/Abuse & 2.353 & 87.868 & 0.021 \\
Social Isolation & 2.152 & 100 & 0.034 \\
Defectiveness / shame & .463 & 100 & 0.645 \\
Failure to achieve & 3.195 & 69.013 & 0.002 \\
Dependence & 4.251 & 100 & 0.000 \\
Vulnerability to harm & 1.993 & 100 & 0.049 \\
Subjugation & 2.457 & 80.048 & 0.016 \\
Self-sacrifice & 0.669 & 100 & 0.505 \\
Emotional inhibition & 4.352 & 100 & 0.000 \\
Enmeshment & 1.235 & 100 & 0.220 \\
Unrelenting standards & 4.221 & 74.707 & 0.000 \\
Entitlement / grandiosity & 0.321 & 100 & 0.749 \\
Insufficient self-control & 1.731 & 100 & 0.086 \\
Whole schemes & 2.072 & 100 & 0.041 \\
\hline
\end{tabular}

The results also showed that total scores of individuals in maladaptive schemas $(t=2.072 ; D F=100 ; P=0.041)$ have statistically significant difference. Significant differences were not observed between the two groups in other schemas.

Table 4: Results of t test for comparison of two groups of patients with obssessive-compulsive personality disorder and healthy control

\begin{tabular}{lccc}
\hline \multirow{2}{*}{ EMSs } & \multicolumn{3}{c}{ t-test for Equality of Means } \\
\cline { 2 - 4 } & $\mathrm{t}$ & $\mathrm{Df}$ & $\mathrm{P}$ value \\
\hline Emotional Deprivation & 4.946 & 68.962 & 0.000 \\
Abandonment & 3.702 & 93.683 & 0.000 \\
Mistrust/Abuse & 5.074 & 49.632 & 0.000 \\
Social Isolation & 6.316 & 94 & 0.000 \\
Defectiveness / shame & 5.155 & 94 & 0.000 \\
Failure to achieve & 9.321 & 46.282 & 0.000 \\
Dependence & 3.916 & 71.590 & 0.000 \\
Vulnerability to harm & 7.602 & 60.201 & 0.000 \\
Subjugation & 0.339 & 94 & 0.735 \\
Self-sacrifice & 0.379 & 71.705 & 0.082 \\
Emotional inhibition & 4.584 & 94 & 0.000 \\
Enmeshment & 4.370 & 94 & 0.000 \\
Unrelenting standards & 5.104 & 47.564 & 0.000 \\
Entitlement / grandiosity & 3.768 & 67.732 & 0.000 \\
Insufficient self-control & 4.825 & 61.046 & 0.000 \\
Whole schemes & 6.431 & 52.274 & 0.000 \\
\hline
\end{tabular}

Testing differences between the patients with obsessive-compulsive personality disorder and healthy individuals is given in Table 4. The results in Table 4 show that patients with obsessive-compulsive personality disorder significantly in the schemas of Emotional Deprivation ( $t=4.946, d f=68.962, p=0.000)$, Abandonment $(t=3.702, d f=93.683, p=0.000)$, Mistrust/ Abuse $(t=5.074, d f=49.632, p=0.000)$, Social Isolation $(t=6.316, d f=94, p=0.000)$, Defectiveness $/$ shame $(t=5.155, d f=94$, 
$p=0.000)$, Failure to achieve $(t=9.321, d f=46.282, p=0.000)$, Dependence $(t=3.916, d f=71.59, p=0.000)$, Vulnerability to harm ( $t=7.602, d f=60.201, p=0.000)$, Emotional inhibition $(t=4.584, d f=94, p=0.000)$, Enmeshment $(t=4.37, d f=94$, $p=0.000)$, Unrelenting standards $(t=5.104, d f=47.564, p=0.000)$, Entitlement / grandiosity $(t=3.768, d f=67.732, p=0.000)$ and Insufficient self-control $(t=4.825, d f=61.046, p=0.000)$ have achieved a higher score. The results also showed that total scores of individuals in maladaptive schemas ( $\mathrm{t}=6.431, \mathrm{DF}=52.274, \mathrm{p}=0.000$ ) have statistically significant difference.

Thus, according to the findings of Table 3 and Table 4, there is sufficient evidence to confirm the second hypothesis that "Maladaptive schemas in obssessive compulsive disorder and patients with obssessive compulsive personality disorder more frequent than in normal subjects."

Table 5: Results of $t$ test for comparison of two groups of patients with obssessive-compulsive personality disorder and obssessive-compulsive disorder

\begin{tabular}{lccc}
\hline & \multicolumn{3}{c}{ t-test for Equality of Means } \\
\cline { 2 - 4 } & $\mathrm{T}$ & $\mathrm{df}$ & $\mathrm{P}$ Value \\
\hline Emotional Deprivation & 5.705 & 62.183 & 0.000 \\
Abandonment & 3.256 & 80 & 0.002 \\
Mistrust/Abuse & 3.489 & 56.063 & 0.001 \\
Social Isolation & 4.130 & 80 & 0.000 \\
Defectiveness / shame & 3.745 & 80 & 0.000 \\
Failure to achieve & 6.412 & 63.555 & 0.000 \\
Dependence & 0.174 & 80 & 0.862 \\
Vulnerability to harm & 6.249 & 57.987 & 0.000 \\
Subjugation & 2.111 & 76.546 & 0.038 \\
Self-sacrifice & 3.825 & 55.229 & 0.000 \\
Emotional inhibition & 1.367 & 80 & 0.176 \\
Enmeshment & 2.897 & 80 & 0.005 \\
Unrelenting standards & 3.573 & 80 & 0.001 \\
Entitlement / grandiosity & 2.021 & 65.529 & 0.047 \\
Insufficient self-control & 3.520 & 61.591 & 0.001 \\
Whole schemes & 4.896 & 58.328 & 0.000 \\
\hline \hline
\end{tabular}

To test the third specific hypotheses, $t$ test was performed for patients with obssessive compulsive disorder and obssessive compulsive personality disorder. Test results (Table 5) show that except the Dependence ( $t=0.06$; $D F=129.995 ; P=0.952)$, ans self-sacrifice $(t=0.00 ; D F=124.792 ; P=1.00)$ schemas, the rest of the 13 early maladaptive schemas, there were significant differences between obssessive compulsive disorder and obssessive compulsive personality disorder groups. The obssessive compulsive personality disorder group significantly obtained higher scores than the obssessive compulsive disorder group in 13 schemes. Also the obssessive compulsive personality disorder group obtained higher scores compared to the healthy control group in the total score of schemas. Thus, sufficient evidence has been obtained to confirm the third specific hypothesis and it can be said that Mean score of maladaptive schemas in patients with obsessive compulsive personality disorder is higher than patients with obsessive-compulsive disorder.

\section{Discussion}

Cognitive theory states that maladaptive schemas may be responsible for certain perceptions of reality and for confirming negative beliefs, which, in turn, can lead to depression and anxiety (Anmuth, \& Haugh, 2011).

In the present study testing the first hypothesis showed that patients with obsessive-compulsive personality disorder and patients and OCD patients with healthy control group have statistically significant differences in the maladaptive schemas. Eta squared coefficient indicates that the effect of group (illness or health) on maladaptive schemas was significant. These results are consistent with the findings of researchers such as Schmidt, Joiner, Young, \& Telch (1995); Jovev and Jackson (2004); Lee, Taylor, \& Dunn (1999); Nordahl, Holthe, and Haugum (2005); Sookman, Pinard, Beck (2003); Atalay, Atalay, Karahan, and Çakiskan (2008); Noie, Asgharnezhad Farid, Fata, \& Ashoori (2010); Kim, Lee \& Lee (2013); esmaeeli, sohrabi, borjali and farokhi (2010); Talee-Baktash, Yaghoubi, \& Yousefi (2013); Wilhelm, Berman, Keshaviah, Schwartz, \& et al. (2015); and Weingarden, \& Renshaw (2015). The second hypothesis 
Testing showed that most of maladaptive schemas in obssessive compulsive disorder and patients with obssessive compulsive personality disorder more frequent than in normal subjects. The results indicate that differences between individuals with obssessive-compulsive disorder and healthy control in schemas of emotional deprivation, mistrust, social isolation, Failure to achieve, Dependence, Vulnerability to harm, Subjugation, Emotional inhibition, and Unrelenting standards were statistically significant. The results also showed that total scores of individuals in maladaptive schemas have statistically significant difference, and patient with obssessive-compulsive obtained higher score than control group. These results are consistent with the findings of researchers such as Sookman, Pinard, Beck (2003); Atalay, Atalay, Karahan, and Çakiskan (2008); Noie, Asgharnezhad Farid, Fata, \& Ashoori, (2010); Kim, Lee \& Lee (2013); esmaeeli, sohrabi, borjali and farokhi (2010); Talee-Baktash, Yaghoubi, \& Yousefi (2013); Wilhelm, Berman, Keshaviah, Schwartz, \& et al. (2015); and Weingarden, \& Renshaw (2015). The third hypothesis testing showed that mean score of maladaptive schemas in patients with obsessive compulsive personality disorder is higher than patients with obsessive-compulsive disorder. These results are consistent with the findings of researchers such as Noie, Asgharnezhad Farid, Fata, \& Ashoori (2010); Nordahl, Holthe, and Haugum (2005); Petrocelli, Glaser, Calhoun, and Campbell (2001); Loper (2003); Sines, Waller, Meyer, and Wigley (2008); Specht, Chapman, and Celluci (2009); Carr and Francis (2010); and Lawrence, Allen, and Chanen (2010). A number of empirical studies found that obsessional personality characteristics were quite distinct from obsessive-compulsive symptoms and that the majority of patients with OCD do not have a premorbid obsessional personality (Clark, 2007). Moreover, certain features of OCPD may be more relevant to OCD than other characteristics of the personality category. For example, perfectionism, a characteristic of OCPD, is significantly elevated in OCD relative to nonclinical controls (Frost \& Steketee, 1997). The study found that compulsive personality disorder and obsessive-compulsive disorder, early maladaptive schemas are much higher than in normal subjects. The study showed that with the exception of self-sacrifice and self-control scheme was insufficient in the early maladaptive schemas 13 patients achieved higher scores in other schemas. The scheme was also inconsistent in patients with obsessivecompulsive personality disorder in 13 patients with obsessive-compulsive disorder was higher maladaptive schemas. The findings indicate that although obsessive-compulsive personality disorder and obsessive-compulsive disorder both associated with high levels of maladaptive schemas, but score of these schemas in two disorders are different and these differences was statistically significant at the 13 schemas. These findings suggest that although the schemes are almost identical in both disorders, but the severity and quality of these schemes is quite different. It can show the difference between these disorders which further research is needed. The effect size in this study shows that in both disorders failure and schemas of vulnerability to harm and illness to have the greatest impact.

Much of the research surrounding specific cognitions and psychopathology has centered on individual disorders that do not encompass the full spectrumof pathology that has become common to clinicians (Hammen, Burge, Daley, Davila, Paley, \& Rudolph, 1995). The present investigation may also provide relevant implications for clinicians who identify maladaptive schemas as a component of schema-focused cognitive therapy (Sperry, 1999). Several study limitations warrant consideration. First, the assessment of all examined constructs relied solely upon self-report. Shared method variance might have inflated the correlations between the measures. In addition, pathoplastic effects of psychopathology on self-image may have influenced the completion of the inventories (Widiger \& Smith, 2008). Second limitation of the present study was use of the short version of the Young schema questionnaire, the Young schema questionnaire-short is only able to measure 15 factors or schemas, but the long version of the questionnaire Yang can measure all 18 early maladaptive schemas.

More research is needed to further evaluate whether the Schema Questionnaires measure what they are intending to measure, namely underlying cognitive structures built early in the development through an interaction between temperament and repeated adverse relationship experiences and serving as templates for processing later experiences (cf. Stopa et al., 2001). In this regard, the development and course of maladaptive schemas and their relationships with psychopathology in childhood and adolescence need more research.

\section{Refrences}

Albert, U., Maina, G., Forner, F., \& Bogetto, F. (2004). DSM-IV obsessive-compulsive personality disorder: prevalence in patients with anxiety disorders and in healthy comparison subjects. Comprehensive Psychiatry, 45(5), 325-332.

Arrindell, W.A., Vlaming, I., Eisenhardt, B., \& Berkum, D. (2002). Cross-cultural validity of the Yale-Brown obsessive compulsive scale. Journal of Behavior Therapy and Experimental Psychiatry, 33, 159-176.

Ataley, H. Ataley, F., Karahan, D. \& Caliskan, M. (2008) Early maladaptive schemas activated in patients with obsessive compulsive disorder: A cross-sectional study. International Journal of Psychiatry in Clinical Practice, 12, 268-279.

Bakhtiary, M. (2000). Surveying mental disorders in patints with body dysmorphic disorder. MA thesis,Clinical psychology, Iran University of Medical Sciences, Tehran Psychiatry Institute, Tehran, Iran. (Persian) 
Barlow, D., \& Durand, V. (2015). Abnormal psychology: An integrative approach. Cengage learning.

Beck, A. T. (1976). Cognitive therapy and the emotional disorders. New York, NY: International Universities Press.

Beck, A. T., Freeman, A., Davis, D. D., \& Ass. (2004). Cognitive therapy of personality disorders (2nd ed.). New York: Guilford Press.

Bighm, A. (2000). Epidemiology of obsessive-compulsive disorder in secondary-School students in Kashan 1999-2000 and its relationship with parenting style. MA thesis, clinical psychology, Tehran psychiatric institute, Tehran University of medical sciences, Tehran, Iran. (Persian)

Calamari, J. E., Wiegartz, P. S., \& Janeck, A. S. (1999). Obsessive-compulsive disorder subgroups: A symptombased clustering approach. Journal of Behaviour Research and Therapy, 37, 113-125.

Calamari, J. E., Chik, H. M., Pontarelli, N. K., \& DeJong, B. L. (2012). Phenomenology and epidemiology of obsessive compulsive disorder. In G. Steketee (Ed.), The Oxford handbook of obsessive compulsive and spectrum disorders (pp. 11-47). New York, NY: Oxford University Press.

Clark, D. A., \& Beck, A. T. (2010). Cognitive therapy of anxiety disorders: Science and practice. New York: The Guilford Press.

Coles, M. E., Pinto, A., Mancebo, M. C., Rasmussen, S. A., \& Eisen, J. L. (2008). OCD with comorbid OCPD: a subtype of OCD?. Journal of psychiatric research, 42(4), 289-296.

Cullen, B., \& Brown, C. H. (2007). Factor analysis of Yale-brown obsessive-compulsive scale in a family study of obsessive compulsive disorder. Journal of Depression and Anxiety, 24(2), 130-138.

Deacon, B., \& Abramowitz, J. (2005). The Yale-Brown obsessive-compulsive scale: Factor analysis, construct validity, and suggestions for refinement. Journal of Anxiety Disorders, 19, 573-585.

Esmaeeli, A., Sohrabi, A. F., Borjali, A., and Farokhi N. (2010) Early Maladaptive Schemas (EMSs) in patients with obsessivecompulsive disorder (OCD). Studies in clinical psychology. 1 (2), 43-25.

Feinstein, S., Fallon, B., Petkova, E., \& Liebowitz, M. (2003). Item by item factor analysis of Yale-Brown obsessive-compulsive scale checklist. Neuropsychiatry Clinical Neuroscience, 15(2), 187-193.

First, M., Spitzer, R., Gibbon, M., \& Williams, J. B. (1996). User's guide for the structured clinical interview for DSM-IV axis I disorders: SCID-I clinician version. Washington, DC: American Psychiatric Association.

Goodman, W. K., Price, L. H, \& Rasmussen, S. A. (1989). The Yale-Brown obsessive-compulsive scale (YBOCS), Part I: Development, use, and reliability. Journal of Archives of General Psychiatry, 46, 1006- 1011.

Guidano, V. F. \& Liotti, G. (1983). Cognitive processes and emotional disorders. New York: Guilford.

Furlong, L. (2006). The role of responsibility beliefs, meta-cognitive beliefs and schemas in obsessive compulsive distress. Ph.D. dissertation.

Jacobsen, D., Kloss, M., Fricke, S., Hand, I., \& Moritz, S. (2003). Reliability of the German version of the Yale- Brown obsessivecompulsive scale. Verhaltenstherapie, 13(2), 111-113.

Kessler, R. C., Berglund, P., Borges, G., Nock, M., \& Wang, P. (2005). Trends in suicide ideation, plans, gestures, and attempts in the United States, 1990-1992 to 2001-2003. JAMA: Journal of the American Medical Association, 293, 2487-2495.

Kessler, R. C., Chiu, W. T., Jin, R., Ruscio, A. M., Shear, K., \& Walters, E. E. (2006). The epidemiology of panic attacks, panic disorder, and agoraphobia in the National Comorbidity Survey Replication. Archives of General Psychiatry, 63(4), 415-424. doi: 10.1001/archpsyc.63.4.415

Kim, J. E., Lee, S. W., \& Lee, S. J. (2014). Relationship between early maladaptive schemas and symptom dimensions in patients with obsessive-compulsive disorder. Psychiatry research, 215(1), 134-140.

Lobbestael, J., Leurgans, M., \& Arntz, A. (2011). Inter rater reliability of the structured clinical interview for DSM-IV axis I disorders (SCID I) and axis II disorders (SCID II). Clinical Psychology \& Psychotherapy, 18(1), 75-79.

Mohammad-Khani, P. (1991). Coping strategies for handling the stress and symptoms in patients with obsessive-compulsive disorder. MA thesis, clinical psychology, Tehran psychiatric institute, Tehran University of medical sciences, Tehran, Iran (Persian).

Mohammadkhani, P., Jokar, M., Jahani-tabesh, O., \& Tamannaei-far, S. (2011). Structured Clinical Interview for DSM-IV Axis II personality disorders (Persian Version).

Mollard, E., Cottraux, J., \& Bouvard, M. (1989). French version of obsessive-compulsive scale. American College Health, 15(3), 335-341.

Moritz, S., Meie, B., \& Kloss. M. (2002). Dimensional structure of Yale-brown obsessive-compulsive scale. Journal of Psychiatry Research, 22, 118-124.

Nakajima, T. (1999). Reliability and validity of the Japanese version of the Yale-Brown obsessivecompulsive scale. Journal of Psychiatry and Clinical Neurosciences, 49, 121-126.

Noie, Z., Farid, A. A., Fata, L., \& Ashoori, A. (2010). Comparison of early maladaptive schemas and their parental origins in OCD patients and non-clinical individuals. Advances in Cognitive Science, 12(1), 59-69.

Olatunji, B. O., Cisler, J. M., \& Tolin, D. F. (2007). Quality of life in the anxiety disorders: A meta-analytic review. Clinical Psychology Review, 27, 572-581.

Pinto, A. (2008). Further development of YBOCS dimensions in the OCD collaborative genetics study: Symptoms vs. category. Journal of Psychiatry Research, 160, 83-93.

Rajezi Esfahani, s., Motaghipour, Y., Kamkari, K., Zahiredin, A., Janbozorgi, M., (2012). Reliability and Validity of the Persian Version of the Yale-Brown Obsessive-Compulsive Scale (Y-BOCS). Iranian Journal of Psychiatry and Clinical Psychology, Vol. 17, No. 4, winter 2012, 297-303.(Persian)

Rosario-Campos, M. C., Miguel, E. C., Quatrano, S., Chacon, P., Ferrao, Y., Findley, D., Katsovich, L., Scahill, L., King, R. A., Woody, S. R., Tolin, D., Hollander, E., Kano, Y., \& Leckman, J. F. (2006). The dimensional Yale-Brown obsessive compulsive scale (DY- 
BOCS): An instrument for assessing obsessive compulsive symptom dimensions. Journal of Molecular Psychiatry, 11(5), 495504.

Rosas. H.J., Vega-Dienstmaier, J. M., Suarez, G. M., Vidal, H., Guimas, B., Adrianzen, C., \& Vivar, R. (2002). Validation of a version in Spanish of the Yale- Brown obsessive-compulsive scale. Journal of Actas Espanolas De Psiquiatrla, 30(1), 30-35.

Sharifi, V., Assadi, S. M., Mohammadi, M. R., Amini, H., Kaviani, H., Semnani, Y., ... \& Jalali, M. (2007). Structured Clinical Interview for DSM-IV (SCID Persian Translation and Cultural Adaptation). Iranian journal of psychiatry, 2(1), 46-48.

Sookman, D., Pinard, G., \& Beck, A. T. (2001). Vulnerability schemas in obsessive-compulsive disorder. Journal of Cognitive Psychotherapy, 15(2), 109-130.

Starcevic, V., Berle, D., Brakoulias, V., Sammut, P., Moses, K., Milicevic, D., \& Hannan, A. (2013). Obsessive-compulsive personality disorder co-occurring with obsessive-compulsive disorder: Conceptual and clinical implications. Australian and New Zealand Journal of Psychiatry, 47(1), 65-73.

Stein, D., Andersen, E., \& Overo, K. (2007). Response of symptom dimensions in obsessive-compulsive disorder to treatment with Citalopram or placebo. Journal of Revista Brasileira de Psiquiatria, 29 (4), 303-307.

Storch, E. A., Shapira, N. A., Dimoulas, E., Geffken, G. R., Murphy, T. K. \& Goodman, W. K. (2005). Yale- Brown obsessive-compulsive scale: The dimensional structure. Journal of Depression and Anxiety, 22(1), 28-35.

Talee-Baktash S, Yaghoubi H, YousefiR. Comparing the early maladaptive schemas and cognitive emotion regulation strategies in obsessive-compulsive disorder patients and healthy people.Feyz2013; 17(5): 471-81.

Tek, C., Ulu, B., \& Gürsoy Rezaki, N. (1995). Yale-Brown obsessive-compulsive scale and US national institute of mental health global obsessive-compulsive scale in Turkish: Reliability and validity. Acta Psychiatrica Scandinavica, 91(6), 410-413.

Weingarden, H., \& Renshaw, K. D. (2015). Shame in the obsessive compulsive related disorders: A conceptual review. Journal of affective disorders, 171(0), 74-84. doi: http://dx.doi.org/10.1016/j.jad.2014.09.010

Widiger, T. A., \& Smith, G. T. (2008). Personality and psychopathology. In O. P. John, R. W. Wilhelm, S., Berman, N. C., Keshaviah, A., Schwartz, R. A., \& Steketee, G. (2015). Mechanisms of change in cognitive therapy for obsessive compulsive disorder: Role of maladaptive beliefs and schemas. Behaviour Research and Therapy, 65(0), 5-10. Doi: http://dx.doi.org/10.1016/j.brat. 2014.12.006.

Wilhelm, S., Berman, N. C., Keshaviah, A., Schwartz, R. A., \& Steketee, G. (2015). Mechanisms of change in cognitive therapy for obsessive compulsive disorder: Role of maladaptive beliefs and schemas. Behaviour Research and Therapy, 65(0), 5-10. doi: http://dx.doi.org/10.1016/j.brat.2014.12.006

Woody, S. R, Steketee, G., \& Chambless, D. L. (1994). Reliability and validity of the Yale-Brown obsessivecompulsive scale. Journal of Behavior Research Therapy, 33, 597-605.

Young, J. E. (1990). Cognitive therapy for personality disorders: A schema-focused approach. Sarasota, FL: Professional Resource Exchange.

Young, J. E., Klosko, J. S., \& Weishaar, M. E. (2003). Schema therapy: A practitioner's guide. New York: The Guilford Press.

Young, J. E. (1999). Cognitive therapy for personality disorders: A schema-focused approach (3rd ed.). Sarasota, FL: Professional Resource Press. 